\title{
UTILIZAÇÃO DE METAS DE DESEMPENHO LIGADAS À TAXA DE EVASÃO ESCOLAR NAS UNIVERSIDADES PÚBLICAS
}

\section{APPLICATION OF PERFORMANCE GOALS RELATED TO THE SCHOOL DROPOUT INDICATOR IN GOVERNMENT UNIVERSITIES}

\section{UTILIZACIÓN DE METAS DE DESEMPEÑO RELACIONADAS A LA TASA DE EVASIÓN ESCOLAR EN LAS UNIVERSIDADES PÚBLICAS}

\begin{abstract}
ORION AUGUSTO PLATT NETO
Professor Adjunto do Departamento de Ciências Contábeis da Universidade Federal de Santa Catarina (UFSC). Contador, Mestre em Gestão de Negócios e Doutor em Inteligência Organizacional (EPS/UFSC). Ex-Contador e Auditor do Serviço Público Federal. orionplatt@yagoo.com.br
\end{abstract}

\section{FLÁVIO DA CRUZ}

Professor Titular do Departamento de Ciências Contábeis da UFSC. Contador, Mestre em Administração Pública (CPGA/UFSC). Contador e Mestre em Administração Pública (CPGA/UFSC). Ex-contador de prefeituras, ex-servidor do Tribunal de Contas de Santa

E-mail: flacruz9@ativanet.com.br

\section{ELISETE DAHMER PFITSCHER}

Professora Adjunta do Departamento de Ciências Contábeis da UFSC. Contadora, com Mestrado e Doutorado em Engenharia de Produção (EPS/UFSC). Atualmente é coordenadora de monografias do Curso de Ciências Contábeis da UFSC e avaliadora de projetos do FUNGRAD e de artigos da Revista Contemporânea de Contabilidade e do SIMPEP. elisete@cse.ufsc.br

\section{RESUMO}

A evasão escolar é apurada e acompanhada como indicador de desempenho em muitas instituições de ensino. Este artigo tem o objetivo de abordar os problemas e os riscos rela- 
cionados à utilização do índice de evasão escolar como meta para avaliação de desempenho institucional no contexto do ensino superior público, e propor formas para percepção da questão conforme a natureza das suas causas. Quanto a sua natureza, a pesquisa é classificada como aplicada, com uma abordagem baseada no método qualitativo. Os resultados atingidos decorrem da apresentação de considerações que permitiram, entre outros aspectos: (a) caracterizar diferenças de contexto para análise da evasão no ensino superior; (b) alertar sobre os riscos institucionais de se adotar o índice de evasão escolar com pressupostos simplistas para análise; e (c) propor uma forma para percepção da questão da evasão que identifica e separa os fatores entre controláveis e não controláveis. Com base nas distinções apresentadas, constata-se que para gerenciar a evasão escolar deve-se, inicialmente, dimensionar a expressividade dos fatores motivadores da evasão que estão "fora do controle" institucional. Nesse sentido, foi proposto um ajuste metodológico no indicador de evasão escolar.

Palavras-chave: Evasão Escolar; Ensino Superior; Avaliação de Desempenho.

\section{ABSTRACT}

School dropout is measured and accompanied as a performance indicator in many educational institutions. This paper aims to approach the problems and risks related to the use of the school dropout indicator as a goal for the evaluation of institutional performance, in the context of government universities, and to propose ways to understand the nature of the causes. This is an applied research, with the approach based on the qualitative method. The results elapsed the presentation of information that allowed, among others aspects: (a) to characterize the differences of context for analysis of the school dropout in universities; (b) to warn about the organizational risks of adopting a school dropout indicator with mistaken parameters of analysis; e (c) to propose a form for perception of the school dropout matter that identifies and separates between the controllable and not controllable factors. Based on such distinctions, in order to manage the school dropout it is necessary, initially, to measure the expressivity of the motivator factors of the evasion that are "out of the organizational control". This way, a methodological adjustment in the school dropout indicator was proposed.

Keywords: School Dropout; Superior Education; Performance Measurement.

\section{RESUMEN}

La evasión escolar es apurada y acompañada como indicador de desempeño en muchas instituciones de enseñanza. Este artículo tiene el objetivo de abordar los problemas y los riesgos relacionados a la utilización del índice de evasión escolar como meta para evaluación de desempeño institucional en el contexto de la enseñanza superiora 
pública, y proponer formas para percepción de la cuestión conforme la naturaleza de sus causas. En cuanto a su naturaleza, la pesquisa es clasificada como aplicada, con un abordaje basado en el método cualitativo. Los resultados alcanzados derivan de la presentación de consideraciones que permitieron, entre otros aspectos: (a) caracterizar diferencias de contexto para análisis de la evasión en la enseñanza superiora; (b) alertar sobre los riesgos institucionales de adoptarse el índice de evasión escolar con supuestos simplistas para análisis; y (c) proponer una forma para percepción de la cuestión de la evasión que identifica y despega los factores entre dominables y no dominables. Con base en las distinciones presentadas, se constata que para dirigir la evasión escolar se debe, inicialmente, dimensionar la expresividad de los factores motivadores de la evasión que están "fuera del control" institucional. En ese sentido, fue propuesto un ajuste metodológico en el indicador de evasión escolar.

Palabras-Clave: Evasión Escolar; Enseñanza Superiora; Evaluación de Desempeño.

\section{INTRODUÇÃO}

O índice de evasão escolar é apurado e acompanhado como indicador de desempenho em muitas instituições de ensino. Verifica-se, nesse contexto, um pressuposto amplamente disseminado na análise do índice, de que a evasão é simplesmente "ruim" e que deve, portanto, ser reduzida ao "máximo". Nessa linha de raciocínio, costuma ser visto como fator relevante do insucesso institucional quando o índice de evasão se eleva ou fica acima da média de outras instituições ou de metas com as quais é feita a comparação.

Este artigo tem o objetivo de abordar os problemas e os riscos relacionados à utilização do índice de evasão escolar como meta para avaliação de desempenho institucional, no contexto do ensino superior público, e propor formas para a percepção da questão, conforme a natureza das causas.

Para cumprimento do objetivo estabelecido, neste artigo são apresentadas considerações que visam:

a) caracterizar as diferenças de contexto para análise da evasão no ensino superior, quando comparado aos níveis de ensino fundamental e médio;

b) alertar sobre os riscos institucionais de se adotar o índice de evasão escolar com pressupostos simplistas para análise de desempenho;

c) propor uma forma para percepção da questão da evasão que identifica e separa os fatores da evasão entre controláveis e não controláveis;

d) identificar alguns fatores (motivos) para evasão escolar no nível superior que estão fora do controle das instituições; 
e) identificar alguns possíveis fatores para evasão escolar no nível superior, que podem ser controlados em algum nível pelas instituições; e

f) apresentar recomendações para pesquisas futuras que possam subsidiar com dados e informações as análises propostas sobre fatores de evasão escolar no ensino superior.

O pressuposto citado sobre a análise da evasão escolar apresenta, possivelmente, uma legitimidade maior no contexto dos níveis de ensino fundamental e médio, em função de estes serem entendidos como etapas mínimas para alfabetização, construção da cidadania e habilitação para funções simples de trabalho.

Deste modo, o pressuposto mencionado e o grau de cobrança sobre o índice de evasão encontram-se em contextos bem diferentes quando analisados em Instituições de Ensino Superior (IES), sejam elas públicas ou privadas. Diversos são os motivos que tornam os contextos diferentes, os quais são abordados adiante.

Muitos dos fatores (motivos) que conduzem os alunos à evasão escolar do ensino superior não são controláveis pela instituição. Desse modo, a instituição e seus colaboradores não podem ser prejudicados com base na avaliação de metas simples de evasão que desconsiderem a natureza dos motivos (controláveis e não controláveis, conforme defendido adiante).

\section{REVISÃO DE LITERATURA}

Nesta seção, são apresentados subsídios básicos para compreensão da importância e da mensuração da evasão escolar no ensino superior. Primeiramente, é destacada a importância de se dispor de informações e de controlar a evasão escolar. Em seguida, são abordadas as principais formas de se medir a questão: a Taxa de Conclusão de Cursos de Graduação (do Programa de Apoio a Planos de Reestruturação e Expansão das Universidades Federais - REUNI); a Taxa de Sucesso na Graduação (do TCU); e a Taxa de Evasão Total. Destaca-se que, apesar de não ter havido uma investigação aprofundada na literatura sobre as causas da evasão, as fontes consultadas sobre o tema são citadas diretamente na seção 4 (Resultados).

\subsection{Importância dos dados e das informações sobre a evasão escolar}

Diversos fatos embasam a importância de se medir e se reduzir a evasão escolar, destacando o valor de sua informação para as instituições de ensino, particularmente para as financiadas com recursos públicos. Podem ser citados os seguintes motivos como os principais, por envolverem:

a) o uso de recursos públicos, aumentando o custo por aluno e deixando capacidade ociosa em fases mais adiantadas dos cursos, que acabam não sendo preenchidas; 
b) a formação e as possibilidades profissionais e sociais de indivíduos que, sob alguns pontos de vista, podem ser considerados "limitados" por abrir mão de uma formação de nível superior; e

c) custos para os alunos, que ao desistirem do curso teriam, em algum grau (nunca completamente), desperdiçado tempo e dinheiro numa formação incompleta. Não é correto, naturalmente, questionar os aprendizados construídos por quem desiste dos cursos.

Tendo em vista os argumentos apresentados, pode-se entender que informações sobre a evasão escolar podem e devem subsidiar políticas públicas na área de educação, mas com os devidos critérios, conforme está destacado nas seções seguintes.

A Constituição Federal de 1988 trata da educação no seu Título VIII (Da Ordem Social), Capítulo III (Da Educação, Da Cultura e Do Desporto), Seção I (Da Educação). Merecem destaque nesta pesquisa os artigos 205 e 206, transcritos parcialmente:

Art. 205. A educação, direito de todos e dever do Estado e da família, será promovida e incentivada com a colaboração da sociedade, visando ao pleno desenvolvimento da pessoa, seu preparo para o exercício da cidadania e sua qualificação para o trabalho.

Art. 206. O ensino será ministrado com base nos seguintes princípios:

I - igualdade de condições para o acesso e permanência na escola;

II - liberdade de aprender, ensinar, pesquisar e divulgar o pensamento, a arte e o saber;

III - pluralismo de idéias e de concepções pedagógicas, e coexistência de instituições públicas e privadas de ensino;

IV - gratuidade do ensino público em estabelecimentos oficiais;

V - valorização dos profissionais da educação escolar, garantidos, na forma da lei, planos de carreira, com ingresso exclusivamente por concurso público de provas e títulos, aos das redes públicas;

VI - gestão democrática do ensino público, na forma da lei;

VII - garantia de padrão de qualidade.

$[\ldots]$

Observa-se entre os princípios que embasam o ensino: (I) igualdade de condições para o acesso e permanência na escola; e (VI) gestão democrática do ensino público, na 
forma da lei; e (VII) garantia de padrão de qualidade. Desse modo, o Estado deve assegurar condições de igualdade não apenas para o acesso, mas também para a permanência na instituição de ensino. Os outros dois princípios serão mencionados adiante.

Por restrição de espaço, outros importantes aspectos constitucionais sobre educação não poderão ser citados, o que não reduz suas importâncias na análise do tema central deste artigo.

\subsection{O REUNI e alguns dados sobre evasão}

Dados do Instituto Nacional de Estudos e Pesquisas Educacionais (INEP, 2003), relativos a 2002 , mostram que a evasão atinge $40,7 \%$ no ensino fundamental e $26 \%$ no ensino médio. Desse modo, de cada cem alunos que ingressam na $1^{\text {a }}$ série do ensino fundamental, apenas 59 concluem a $8^{\circ}$ série.

Ainda conforme o INEP, no que tange ao ensino superior, entre 1980 e 1996: o número de matrículas aumentou em mais de $36 \%$; o número de vagas cresceu em $60 \%$; o número de concluintes cresceu $12 \%$; e dos alunos que ingressam, $40 \%$ não concluem os cursos.

O Censo da Educação Superior, realizado pelo INEP (2007), revelou que no ano de 2004 (último ano disponível para acesso na internet), realizaram matrícula no ensino superior 4.163.733 indivíduos. Apenas 528.102 indivíduos concluíram seus cursos no mesmo ano, o que representa $12,7 \%$ dos matriculados no mesmo ano.

Apesar das estatísticas apresentadas, Gaioso (2005) verificou que há grande diferença entre os dados oficiais da evasão e as informações obtidas nas entrevistas com dirigentes das IES e com estudantes evadidos. A questão chega a ser tratada como tabu, em função do receio de que o nome da instituição seja colocado em risco em face da elevada evasão.

No ano de 2007, por meio do Decreto $n^{\circ} 6.096$, de 24 de abril, o Presidente da República instituiu o Programa de Apoio a Planos de Reestruturação e Expansão das Universidades Federais, conhecido também pela sigla REUNI.

O artigo $1^{\circ}$ do Decreto $n^{\circ} 6.096 / 07$ define o objetivo e a meta global do REUNI:

Art. $1^{\circ}$ Fica instituído o Programa de Apoio a Planos de Reestruturação e Expansão das Universidades Federais - REUNI, com o objetivo de criar condições para a ampliação do acesso e permanência na educação superior, no nível de graduação, pelo melhor aproveitamento da estrutura física e de recursos humanos existentes nas universidades federais.

$\S 1^{\circ} \mathrm{O}$ Programa tem como meta global a elevação gradual da taxa de conclusão média dos cursos de graduação presenciais para noventa por cento e da relação de alunos de graduação em cursos presenciais por professor para dezoito, ao final de cinco anos, a contar do início de cada plano. 
$\S 2^{\circ} \mathrm{O}$ Ministério da Educação estabelecerá os parâmetros de cálculo dos indicadores que compõem a meta referida no $\S 1^{\circ}$.

Assim, o objetivo do REUNI é criar condições para a ampliação do acesso e da permanência na educação superior, no nível de graduação, pelo melhor aproveitamento da estrutura física e de recursos humanos existentes nas universidades federais.

A meta global do Programa ataca diretamente a evasão escolar: elevação gradual da taxa de conclusão média dos cursos de graduação presenciais para $90 \%$ e da relação de alunos de graduação em cursos presenciais por professor para 18, ao final de 5 anos.

O REUNI apresenta as seguintes diretrizes (Decreto $n^{\circ} 6.096 / 07$, art. $2^{\circ}$ ): (a) redução das taxas de evasão, ocupação de vagas ociosas e aumento de vagas de ingresso, especialmente no período noturno; (b) ampliação da mobilidade estudantil, com a implantação de regimes curriculares e sistemas de títulos que possibilitem a construção de itinerários formativos, mediante o aproveitamento de créditos e a circulação de estudantes entre instituições, cursos e programas de educação superior; (c) revisão da estrutura acadêmica, com reorganização dos cursos de graduação e atualização de metodologias de ensino-aprendizagem, buscando a constante elevação da qualidade; (d) diversificação das modalidades de graduação, preferencialmente não voltadas à profissionalização precoce e especializada; (e) ampliação de políticas de inclusão e assistência estudantil; e (f) articulação da graduação com a pós-graduação e da educação superior com a educação básica.

Merece destaque no âmbito deste estudo o fato de o Programa buscar a redução das taxas de evasão e a ampliação de políticas de inclusão e assistência estudantil.

O documento intitulado "Diretrizes Gerais do Programa de Apoio a Planos de Reestruturação e Expansão das Universidades Federais - REUNI" começou a ser difundido no País a partir de agosto de 2007. Tal documento foi elaborado pelo Grupo Assessor nomeado pela Portaria $\mathrm{n}^{\circ} 552$ SESu/MEC, de 25 de junho de 2007, em complemento ao art. $1^{\circ}$, $\S 2^{\circ}$, do Decreto Presidencial n 6.096/07.

Referido Grupo Assessor, vinculado à Secretaria de Educação Superior, do Ministério da Educação (MEC), apresenta, entre outros aspectos, um diagnóstico da educação superior brasileira, que merece destaque (MEC, 2007, p.7-8):

No plano operacional, algumas constatações acerca de aspectos problemáticos da estrutura e funcionamento repetem, aprofundam e amplificam o conjunto de problemas estruturais herdados do velho regime de formação, tais como:

\section{$[\ldots]$}

Os índices de evasão de estudantes nos cursos de graduação atingem, em alguns casos, níveis alarmantes. 
Em suma, estreitos campos do saber contemplados nos projetos pedagógicos, precocidade na escolha dos cursos, altos índices de evasão de alunos, descompasso entre a rigidez da formação profissional e as amplas e diversificadas competências demandadas pelo mundo trabalho e, sobretudo, os novos desafios da sociedade do conhecimento são problemas que, para sua superação, requerem modelos de formação profissional mais abrangentes, flexíveis e integradores.

Assim, o diagnóstico governamental é de que os índices de evasão de estudantes nos cursos de graduação atingem, em alguns casos, níveis alarmantes. É altamente recomendada a leitura do documento para um entendimento de outros aspectos da situação que motivou, para o Governo Federal, a criação do REUNI.

O Decreto do REUNI privilegiou dois indicadores de desempenho para aferição das metas do programa: a taxa de conclusão média dos cursos de graduação; e a relação de alunos de graduação em cursos presenciais por professor. Conforme definido no $\S 2^{\circ}$ do art. $1^{\circ}$, o Ministério da Educação estabelecerá os parâmetros de cálculo dos indicadores.

\subsubsection{Taxa de Conclusão dos Cursos de Graduação, do REUNI}

A definição do MEC (2007, p.14) para o indicador de taxa de conclusão dos cursos de graduação é a seguinte:

A taxa de conclusão dos cursos de graduação é um indicador calculado anualmente por meio da razão entre diplomados e ingressos. O valor de TCG não expressa diretamente as taxas de sucesso observadas nos cursos da universidade, ainda que haja uma relação estreita com fenômenos de retenção e evasão. Na verdade TCG também contempla a eficiência com que a universidade preenche as suas vagas ociosas decorrentes do abandono dos cursos.

A equação definida para apuração do indicador é a constante no quadro a seguir.

\section{Quadro 1: Equação para o indicador de Taxa de Conclusão dos Cursos de Graduação para medição de metas do REUNI}

Taxa de Conclusão dos Cursos de Graduação (TCG):

Relação entre o total de diplomados nos cursos de graduação presenciais (DIP) num determinado ano e o total de vagas de ingresso oferecidas pela instituição (ING5) cinco anos antes.

$$
\mathrm{TCG}=\frac{\mathrm{DIP}}{\mathrm{ING}_{5}}
$$

Fonte: Adaptado de MEC (2007, p.14). 


\subsubsection{Taxa de Sucesso na Graduação, do TCU}

Outro indicador que evidencia o impacto da evasão escolar nos cursos de graduação é o de "Taxa de Sucesso na Graduação (TSG)", cuja apuração é exigida de todas as Instituições Federais de Ensino Superior (IFES) por parte do Tribunal de Contas da União (TCU). O TCU auxilia o Congresso Nacional no exercício do controle externo, previsto a partir do art.70 da Constituição Federal de 1988.

No dia 8/5/2002, foi aprovada a ata da sessão plenária do Tribunal de Contas da União, que exarou a Decisão TCU n 408/2002 - Plenário. Referida Decisão do TCU determinou que as Instituições Federais de Ensino Superior (IFES) elaborassem uma série de indicadores de desempenho.

Foi determinado que tais indicadores fossem incluídos nos relatórios de gestão das IFES a partir do ano de 2002, sendo que tais relatórios compõem o processo de prestação de contas das instituições.

A Decisão determinou ainda a constituição de "Grupo de Contato", formado por representantes do TCU, da Secretaria de Educação Superior (SESu/MEC) e da Secretaria Federal de Controle Interno (SFC). Os objetivos do Grupo de Contato são: orientar as IFES na implantação padronizada do conjunto inicial de indicadores e definir plano de ação com vistas a aprimorá-los.

O conjunto inicial de indicadores foi selecionado com base em auditoria de natureza operacional realizada na Universidade de Brasília (UnB). A fiscalização teve por objetivo a seleção e a apuração de indicadores que pudessem retratar aspectos relevantes do desempenho das IFES.

A etapa subseqüente, sob a responsabilidade do Grupo de Contato, foi a de padronizar a implantação dos indicadores nos relatórios de gestão das IFES.

A análise realizada quando do processo de consolidação das auditorias evidenciou algumas limitações e cuidados que devem acompanhar a utilização e a interpretação dos resultados obtidos, conforme descrito pelo Grupo de Contato (2006):

Devido à grande heterogeneidade apresentada pelas IFES, o conjunto de indicadores, pela sua simplicidade, mostrou-se incapaz de, isoladamente, permitir conclusões sobre o desempenho das instituições. Com essa perspectiva como ponto de partida, a Decisão do TCU não teve por objetivo a obtenção de dados para avaliação da condução gerencial da IFES. Tão pouco há intenção de estabelecer classificação hierárquica e alternativa de instituições, duplicando-se o trabalho já sistematicamente realizado pela SESu.

Desse modo, a finalidade dos indicadores, diante as limitações destacadas, é construir séries históricas para acompanhar a evolução de aspectos relevantes do desempenho de todas as IFES. Ao longo dos anos, tais séries históricas poderão indicar a neces- 
sidade de aperfeiçoamentos em áreas específicas, ou mesmo a correção de eventuais disfunções. Assim, as informações gerenciais extraídas do acompanhamento poderão servir de subsídio para selecionar áreas a serem estudadas em maior profundidade pelos órgãos de Controles Interno e Externo.

Segundo o Grupo de Contato (2006), essa seleção de dados históricos:

orientará trabalhos como a análise das Contas do Governo e auditorias de natureza operacional, direcionadas à identificação de boas práticas e de oportunidades de melhoria na gestão. No mesmo sentido, esses dados poderão ser utilizados pelo Ministério da Educação, no monitoramento já realizado das ações e resultados das IFES. Espera-se também que o acompanhamento da evolução desses indicadores possa ser útil como ferramenta de apoio à necessária auto-avaliação institucional.

Conseqüentemente, os indicadores devem ser considerados apenas como ferramenta auxiliar no acompanhamento do desempenho das entidades.

O cálculo da Taxa de Sucesso na Graduação é apurado de acordo com a Decisão TCU n 408/2002, com os Acórdãos TCU n 1.043/2006 e n².167/2006, e orientações do Grupo de Contato, com metodologia sintética constante no Quadro 2.

Quadro 2: Equação para o indicador Taxa de Sucesso na Graduação, do TCU

Taxa de Sucesso na Graduação (TSG):

O número de diplomados, também chamados de concluintes, considera apenas os ingressantes via concurso vestibular, levando em conta a duração média de cada curso. Para contagem do número de ingressantes é calculado o ano de ingresso do aluno em seus respectivos cursos, ou seja, depende da duração de cada curso.

$$
\operatorname{TSG}=\frac{\mathrm{N}^{\circ} \text { de Diplomados }\left(\mathrm{N}_{\mathrm{DI}}\right)}{\mathrm{N}^{0} \text { Total de Alunos Ingressantes }}
$$

Fonte: Adaptado de Grupo de Contato (2006, p.25-26) e de UFSC (2007, p.91).

Como forma de ilustrar o cálculo, de maneira simples, seguem dados da Universidade Federal de Santa Catarina, divulgados no ano de 2007 em seu relatório de Gestão referente ao ano de 2006 (UFSC, 2007, p.91):

a) Número de diplomados (concluintes) $=2.688$.

b) Número de ingressantes via vestibular (referente ao período padrão de duração dos cursos) $=3.880$.

c) Taxa de Sucesso na Graduação (TSG): 2.688 / $3.880=0,69$. 
Deste modo, pode-se dizer que para cada 100 alunos que ingressam na UFSC via vestibular, 69\% concluem seus cursos nos prazos de padrões de duração. Assim, os restantes $31 \%$ não apresentam o sucesso medido na conclusão dos seus cursos no prazo.

Observa-se que este índice não contempla a evasão escolar em sua plenitude, tendo em vista que alguns alunos concluem o curso em semestres posteriores. Todavia, ao longo de uma série histórica tais descompassos podem se compensar.

\subsubsection{Taxa de Evasão Total}

Pode-se, ainda, apurar um índice mais simples de evasão, que será revisto em seção posterior, diante de uma proposta alternativa para analisar os fatores causadores da evasão. O Quadro 3 apresenta uma metodologia preliminar e sintética.

\section{Quadro 3: Equação para a Taxa de Evasão Total}

\begin{tabular}{|c|}
\hline Taxa de Evasão Total (TET): \\
\hline Número total de alunos evadidos (NE) dividido pelo número total de alunos ingressantes (NI). \\
\hline TET $=\frac{\mathrm{NE}}{\mathrm{NI}}$ \\
\hline
\end{tabular}

Fonte: Elaborado pelos autores.

Detalhes metodológicos precisarão ser definidos e aprimorados com a participação das instituições, visando aumentar a gestão democrática e inibir conduções unilaterais de instrumentos de medida, o que poderia comprometer a legitimidade e a aceitação do indicador.

\section{PROCEDIMENTOS METODOLÓGICOS}

Quanto a sua natureza, a pesquisa apresentada é classificada como aplicada, com uma abordagem baseada no método qualitativo. Quanto aos objetivos, trata-se de uma pesquisa exploratória. A visão de conhecimento assumida é construtivista e o paradigma científico é fenomenológico.

Este artigo pode ser considerado incipiente e limitado em termos quantitativos e também no uso de instrumentos de pesquisa, no que se refere à mensuração dos fatores apontados. Também não houve aprofundamento na revisão de literatura sobre os motivos e os dados sobre evasão no ensino superior no Brasil e em outros países. Nesse sentido, o estudo também se valeu de conhecimentos, experiências e da expressão de valores dos autores, todos eles professores de uma universidade federal brasileira.

Desse modo, as limitações deste trabalho são as inerentes a uma abordagem qualitativa, na qual os pesquisadores desempenham papel crucial na análise dos dados e infor- 
mações. Assim sendo, destaca-se que não há a pretensão de se esgotar as motivações e as proposições de alternativas para avaliar a evasão escolar.

Buscou-se estimular o entendimento diferenciado sobre idéias defendidas e a controvérsia sobre o tema. Isso foi feito por meio de analogias, ilustrações desafiadoras e do confronto de pressupostos disseminados sobre a evasão escolar. Desse modo, exige-se uma leitura crítica por parte do leitor.

O trabalho se inicia com a identificação e a construção de uma problemática para a questão da avaliação institucional com base em índices de evasão escolar. Em seguida, são analisados pressupostos e critérios de avaliação que são questionados. Foi realizada uma revisão de literatura de caráter principiante, visando oferecer informações que destacassem apenas a relevância do tema.

O trabalho seguiu com a identificação de alguns fatores (motivações) para a evasão escolar no ensino superior. A partir da caracterização dos referidos fatores, foi proposta uma abordagem para percepção do problema da evasão, com distinções claras entre fatores controláveis e não controláveis pelas instituições de ensino superior.

Por fim, junto às conclusões do estudo, são apresentadas recomendações para pesquisas futuras que possam subsidiar com dados e informações as análises sobre fatores de evasão escolar no ensino superior público.

\section{RESULTADOS}

Nesta seção, busca-se inicialmente caracterizar as diferenças de contexto para análise da evasão escolar no ensino superior, quando comparado com os níveis de ensino fundamental e médio. Em seguida são identificados alguns fatores (motivos) para evasão escolar no nível superior que estão fora do controle das instituições. Os pressupostos e os motivos identificados constituem a base para a proposição de uma forma para percepção da questão que identifica e separa os fatores da evasão conforme o grau de controle que a instituição dispõe. A partir da compreensão desenvolvida, são propostas formas possíveis para atuação sobre os fatores controláveis da evasão.

\subsection{Diferenciação de contexto nos níveis e ensino}

É possível se identificar alguns motivos importantes que caracterizam a diferença de contexto de análise da evasão no ensino superior em relação aos níveis de ensino fundamental e médio:

a) não há exigência legal para que os cidadãos cursem o ensino superior, o que caracteriza sua livre opção de continuidade na formação;

b) não há obrigação de a administração pública oferecer vagas de ensino superior 
para todos os cidadãos, ou seja, não há pretensão de universalização gratuita do acesso às instituições de ensino superior; e

c) nada impede que o estudante mude sua opção de curso de nível superior após ingressar num deles, por diversos motivos abordados adiante.

Desse modo, taxas menores de evasão são particularmente mais importantes nos níveis de ensino fundamental e médio, em função de estes serem entendidos como etapas mínimas para construção da cidadania, por meio da alfabetização e da habilitação para funções simples de trabalho.

\subsection{Motivos para evasão escolar que estão fora do controle institucional}

Muitos dos motivos para a evasão escolar no ensino superior não são controláveis pela instituição, ou têm um grau de controle baixo se comparados a outros. Segue uma lista de "possíveis motivos" para haver evasão escolar, sem a pretensão de se esgotarem os fatores, nem de se imporem verdades absolutas:

a) falta de vocação do estudante para a área profissional, motivada por falta de visão de mundo e de mercado quando da realização da sua escolha;

b) necessidade de o estudante auxiliar sua família ou constituir uma, com demanda de cuidado de filhos e/ou outros parentes;

c) necessidade de sustentar financeiramente e com trabalho a sua família, implicando sacrifício do estudo (entre outros);

d) dependência, por parte do aluno, de atividade econômica ou emprego que exija viagens que prejudiquem seus estudos, com descaso de seu empregador ou quando inerente ao seu cargo ou função;

e) falta de perfil do aluno para se "formar" numa área de atuação profissional;

f) incapacidade intelectual do aluno nas habilidades que possam ser exigidas em determinadas áreas do curso, tais como raciocínio lógico e disciplina para pesquisas;

g) abandono do curso numa instituição para imediato ingresso em outra, no mesmo curso de formação ou não;

h) doença grave e morte. Vamos criar e conceder um "diploma post-mortem" para burlar o índice de evasão?

No que tange aos itens "a", "e" e "f", merece destaque a ressalva de que a permanência de alunos desinteressados ou com baixa condição para acompanhamento dos conteúdos e atividades (por motivos diversos) pode contribuir para a desmotivação dos demais alunos e prejudicar o andamento com alto nível das aulas. Formação de baixa qualidade e com excesso de tolerância não auxilia os alunos no ambiente competitivo de mercado que 
a maioria enfrentará. Cabe uma avaliação estratégica: vamos plantar "muitas" sementes ou "boas" sementes no solo árido do mundo?

Adicionalmente, deve haver ampla liberdade para a escolha da profissão a ser seguida. Desse modo, a escolha de um curso superior não deve assumir o pressuposto de um casamento religioso tradicional: "até que a morte os separe". Assim, o estudante não deve ser obrigado a ficar no curso "até que a formatura os separe", caso ele se arrependa de sua opção original. Quantas pessoas se formam em cursos que acabam não exercendo nem percebendo muita utilidade? Quantos casamentos infelizes foram mantidos em nome de "princípios de permanência"?

Muitas vezes as decisões de escolha de curso superior são feitas sem uma pesquisa vocacional adequada, nem conhecimento das áreas de atuação profissional. Os indivíduos e o mercado também podem mudar sensivelmente, motivando mudanças estratégicas nas opções profissionais.

Destaca-se novamente que não houve a pretensão, com a lista, de ser exaustivo na identificação de motivos, nem de oferecer verdades inquestionáveis. O ponto chave, aqui, é fixar um entendimento sobre "controle institucional", que será mais bem explorado adiante. Inclusive alguns dos fatores aqui citados serão revistos diante de uma postura institucional pró-ativa.

\subsection{Distinção sobre os fatores motivadores da evasão}

Está sendo proposta a identificação e a separação dos fatores (motivos) da evasão escolar entre "controláveis" e "não controláveis", numa percepção de graus de gerenciamento do desempenho. Todavia, antes de seguir com a distinção de "controle" no contexto específico, é necessário entender a dimensão conceitual do termo. $\mathrm{O}$ ato de controlar está intimamente ligado ao ato de planejar, dando retorno ao processo de planejamento e visando garantir que resultados sejam atingidos por meio da correta aplicação de recursos.

Segundo Cruz e Glock (2007, p. 20), o controle caracteriza-se por:

qualquer atividade de verificação sistemática de um registro,exercida de forma permanente ou periódica, consubstanciado em documento ou outro meio, que expresse uma ação, uma situação, um resultado etc., com o objetivo de verificar se existe conformidade com o padrão estabelecido, ou com o resultado esperado, ou, ainda, com o que determinam a legislação e as normas.

Desse modo, o controle pressupõe um planejamento, a existência de padrões, normas ou resultados esperados, e a verificação sistemática do desempenho. Destaca-se que o controle depende da mensuração de fatos e da autoridade para agir. Sem haver autorida- 
de e recursos para agir corretivamente diante de desvios em relação aos padrões, não há controle, mas apenas um "acompanhamento".

São "controláveis", os fatores sobre os quais a instituição tem total ou maior condição de influenciar a decisão por meio de ações. São "não controláveis" aqueles sobre os quais os esforços da instituição e de seus colaboradores apresentam pouco ou nenhum efeito.

A distinção recomendada pode ser dicotomizada em um tipo ou outro. Na prática, alguns dos fatores (motivos) estão numa escala de graus de influência, com a possibilidade de pender mais para um lado do que para outro. A Figura 1 e os Quadros 4 e 5 oferecem uma noção sobre as formas possíveis e propostas para a percepção da questão.

\begin{tabular}{|c|c|c|c|c|c|c|}
\hline \multicolumn{7}{|c|}{ Motivos para a Evasão } \\
\hline \multirow{3}{*}{$\begin{array}{l}\text { F1* F2 } \\
\leftarrow--\mid-- \\
\text { "Controláveis" }\end{array}$} & F3 & $\mathrm{F} 4$ & F5 & F6 & $\mathrm{F} 7$ & \\
\hline & & -------. & $--\mid--$ & & |------------. & $-\rightarrow$ \\
\hline & & "Mais" & & & "Menos" & "Não Controláveis" \\
\hline
\end{tabular}

Fonte: Elaborado pelos autores.

Figura 1: Escala genérica para posicionamento dos fatores motivadores da evasão escolar conforme o grau de controle institucional

Observa-se que na Figura 1 é proposto um ordenamento dos fatores motivadores da evasão escolar conforme o "grau de controle" que a instituição dispõe para agir sobre as causas e efeitos. Nos extremos, estão os fatores entendidos como os "totalmente" controláveis e os não controláveis. No meio da escala genérica, estão, à esquerda, os fatores sobre os quais se tem "mais controle" e, à direita, os fatores sobre os quais se tem "menos controle".

Observa-se no Quadro 4 a proposta de uma separação simples entre os fatores controláveis e os não controláveis. Tal separação exige simplificação, pois não evidencia os graus de controle (maior ou menor): há, portanto, uma dicotomia para análise. Todavia, apesar da limitação citada, a abordagem pode ser útil num primeiro momento, para seguir com a proposta constante no Quadro 5.

Quadro 4: Separação simples dos fatores motivadores da evasão escolar conforme
o controle institucional
\begin{tabular}{|l|l|}
\hline \multicolumn{2}{|c|}{ Motivos para a Evasão } \\
\hline Controláveis & Não Controláveis \\
\hline Fatores 1, 2, 3 e 4 & Fatores 5, 6, 7 e 8 \\
\hline
\end{tabular}

Fonte: Elaborado pelos autores. 


\section{Quadro 5: Separação priorizada dos fatores motivadores da evasão escolar conforme o controle institucional}

\begin{tabular}{|l|l|l|l|}
\hline \multicolumn{4}{|c|}{ Motivos para a Evasão } \\
\hline Controláveis & Não priorizados & $\begin{array}{l}\text { Não Controláveis } \\
\text { (Não Priorizados) }\end{array}$ \\
\hline Priorizados* & - Fator 3 & - Fator 5 & - Fator 7 \\
\hline - Fator 1 & - Fator 4 & - Fator 6 & - Fator 8 \\
\hline - Fator 2 & * Priorizados em função da melhor relação custo x resultado e/ou das condições institucionais. \\
\hline
\end{tabular}

Fonte: Elaborado pelos autores.

Nota-se que o Quadro 5 é derivado do Quadro 4, com diferenciação na evidenciação de prioridades para orientação das ações institucionais. Desse modo, os fatores não controláveis não são priorizados em função do entendimento de que haveria desperdício de esforços e recursos. Tais fatores precisam ser simplesmente "aceitos" até que surjam alternativas para reclassificação. Por sua vez, os fatores controláveis são agrupados em dois conjuntos: os "priorizados" e os "não priorizados".

Nessa abordagem, serão priorizados os fatores motivadores da evasão que apresentem melhor relação "custo x resultado" e/ou em função das condições institucionais, tais como a disponibilidade de recursos financeiros e humanos para atuação sobre as ações de redução da evasão. Assim, os fatores controláveis poderão migrar de um grupo para outro, conforme a prioridade que institucionalmente for eleita mediante planejamento.

A forma proposta para percepção da evasão permite a definição de metas mais adequadas, em função de permitir considerar apenas a evasão sobre a qual a instituição pode exercer controle (controlável). A Tabela 1 evidencia um exemplo hipotético para apuração das taxas de evasão.

Com base na Tabela 1, podem ser feitas algumas considerações importantes no que tange à definição de metas. As explicações sobre as formas de apuração das diversas variáveis e índices utilizados estão ao final do quadro e são de leitura indispensável para a compreensão das seguintes considerações:

a) não deve haver o pressuposto simplista de que "quanto menor a evasão melhor", tendo em vista que não é possível ou desejável interferir sobre todos os fatores causadores da evasão;

b) além de se identificar a taxa de evasão total (TET), é preciso saber qual a taxa de evasão que pode ser controlada (TEC), ou seja, a que expressa a parcela dos fatores sobre os quais é possível e adequado agir; e

c) a partir da compreensão dos fatores controláveis e das condições operacionais e financeiras da instituição, é possível se definir a taxa de evasão priori- 
zada (TEP), mais adequada para metas de desempenho, desde que definida adequadamente.

\section{Tabela 1: Apurações dos graus de evasão conforme o controle e as prioridades} institucionais

\begin{tabular}{|c|c|c|}
\hline Variáveis Ligadas à Evasão & Dados & Representatividade \\
\hline TET: Taxa de Evasão Total (1) & $\begin{array}{l}\text { NE (Número Evadidos) }=80 \\
\mathrm{NI} \text { (Número de } \\
\text { Ingressantes) }=160\end{array}$ & $50,0 \%$ do $\mathrm{NI}$ \\
\hline $\begin{array}{l}\text { PNC: Parcela Não Controlável da } \\
\text { Evasão }{ }^{(2)}\end{array}$ & 32 dos evadidos & $40,0 \%$ do $\mathrm{NE}$ \\
\hline $\begin{array}{l}\text { PCE: Parcela Controlável da Evasão } \\
\text { (3) }\end{array}$ & NE $-\mathrm{PNC}=48$ dos evadidos & $60,0 \%$ do NE \\
\hline TEC: Taxa de Evasão Controlável (4) & $\mathrm{PCE} / \mathrm{NI}=48 / 160$ & $30,0 \%$ do $\mathrm{NI}$ \\
\hline $\begin{array}{l}\text { PMP: Parcela dos Motivos } \\
\text { Priorizados }{ }^{(5)}\end{array}$ & 36 dos evadidos & $75,0 \%$ do PCE \\
\hline TEP: Taxa de Evasão Priorizada (6) & $\mathrm{PMP} / \mathrm{NI}=36 / 160$ & $22,5 \%$ do $\mathrm{NI}$ \\
\hline
\end{tabular}

Observações:

$1-$ TET $=$ Total de Alunos Evadidos $/$ Total de Alunos Ingressantes. Metade dos alunos abandona o curso.

2 - PNC: soma dos casos de alunos em que os motivos para a evasão foram identificados como "não controláveis" pela instituição.

$3-\mathrm{PCE}=$ NE - PNC. Equivalente à soma dos casos em que os motivos para a evasão foram identificados como controláveis pela instituição. Deste modo, poderia ter havido ações para minimizar este número, e poderá haver no futuro.

4 - TEC = PCE / NI. Grau de evasão sobre o qual a instituição pode exercer controle (controláveis) em relação aos motivos que levaram os alunos a abandonar o curso.

5 - PMP: soma dos casos de alunos em que os motivos para a evasão, além de controláveis, foram definidos como prioridades institucionais para redução (ou eliminação). Os casos de alunos evadidos devem ser categorizados conforme os motivos.

6 - TEP: grau de evasão sobre o qual há prioridade para redução, em função de disponibilidade de recursos e de ações institucionais planejadas.

Fonte: Elaborado pelos autores.

No exemplo da Tabela 1, observa-se a expressividade numérica que consta na Taxa de Evasão Total (TET), que evidencia que metade dos alunos ingressantes abandona o curso. Questiona-se: quais ações poderiam ser realizadas para obter melhores resultados em termos de menor evasão?

\subsection{Atuação sobre os fatores de evasão controláveis}

Tendo sido feita a identificação dos fatores causadores da evasão que são controlá- 
veis, é necessário desenvolver o conhecimento para orientar ações de controle no sentido de se obter resultados que diminuam a evasão.

Em alguns casos, a instituição e seus colaboradores podem ser os responsáveis por parte da evasão. Em outros casos, a instituição poderia ser pró-ativa no auxílio aos alunos e na prevenção de possíveis problemas.

Segue uma lista de possíveis motivos para o aumento da evasão, causadas por práticas conscientes ou inconscientes da instituição, por carência dos alunos e falta de esclarecimento durante o processo decisório. Junto a cada situação (motivação) são colocados exemplos, sugestões ou questionamentos para minimizar cada problema causador da evasão.

a) Exigência exacerbada em disciplinas, que esteja fora da capacidade ou disponibilidade de tempo dos alunos. O Grupo Assessor do MEC (2007, p.8), ao apresentar um diagnóstico de contexto para o REUNI, afirma haver um "descompasso entre a rigidez da formação profissional e as amplas e diversificadas competências demandadas pelo mundo trabalho [sic] [...]". Como medir tal aspecto? Como "nivelar" as exigências das disciplinas?

b) Pouca atenção extraclasse aos alunos interessados em conhecer melhor as possibilidades de carreira, por meio de conversas e participação em eventos.

c) Falta de oportunidades e de motivação para a realização de pesquisas acompanhadas por professores e outros colaboradores da instituição sobre temas de seu interesse no curso.

d) Ausência de assistência social e psicológica efetiva para alunos com problemas que poderiam ser amenizados apenas com a atenção de especialistas.

e) Ausência de assistência financeira a alunos carentes que permaneceriam no curso apenas caso dispusessem de uma bolsa de ensino ou de moradia. Não pode ser confundido com os casos dos alunos que abandonam o curso para sustentar suas famílias ou por exigências de seus empregos. Muitas das instituições já oferecem bolsas de monitoria e iniciação científica, mas ainda em volume insuficiente à demanda. Os dois itens a seguir ganharam destaque nesta categoria.

f) Gastos com livros, materiais e, dependendo do curso, equipamentos caros. A instituição poderia doar materiais didáticos mínimos para minimizar o problema, conforme iniciativa da Universidade do Estado do Rio de Janeiro (UERJ), para alunos quotistas (Schibik, 2005).

g) Gasto com transporte, segundo pesquisa, é um significativo fator motivador de evasão escolar (Schibik, 2005). Pesquisa da Unicamp, em 2001, mostrou que 40\% da evasão escolar têm como principal responsável a falta de condições para pagar o transporte coletivo (Univérsia, 2007). A instituição poderia financiar diretamente o transporte ou fornecer ajuda por meio de bolsas. Pode-se, ainda, realizar parcerias 
ou estimular políticas públicas de atendimento a estudantes carentes com transporte público gratuito ou subsidiado. Os alunos quotistas da UERJ, por exemplo, recebem vale-transporte, além de outros recursos e auxílios (Schibik, 2005).

h) Baixo conhecimento sobre a área de atuação profissional antes de ingressar no curso. A instituição pode oferecer e promover divulgação sobre os cursos antes do ingresso dos alunos, visando minimizar a entrada de pessoas sem interesse ou com desconhecimento.

Nota-se que são muitas as possíveis vias de ação, visando minimizar a evasão dentro de princípios de qualidade de ensino. Algumas das alternativas envolvem recursos financeiros e de pessoal que nem sempre a instituição dispõe na medida ideal. Desse modo, torna-se necessário identificar os pontos mais viáveis para se minimizar a evasão, com boa relação de "custo versus benefício" ou de "custo versus resultado".

Para o conhecimento de outros fatores causadores da evasão, bem como de algumas práticas institucionais, recomenda-se a leitura do estudo feito por Gaioso (2005) para a Unesco, que por restrição de espaço não poderão ser tratados neste artigo.

Para orientar uma ação inteligente no sentido de pró-atividade institucional, pesquisas e análises de casos reais têm mais chance de sucesso.

Para gerenciar a evasão, deve-se, inicialmente, dimensionar a expressividade dos fatores motivadores da evasão que estão "fora do controle" institucional. Essa margem de motivos "não controláveis" deve ser simplesmente aceita como variável ambiental, salvo caso surja alguma forma alternativa de entender a questão.

\section{CONCLUSÃO}

Este artigo abordou os problemas e os riscos relacionados à utilização do índice de evasão escolar como meta para avaliação de desempenho institucional, no contexto do ensino superior público, e propôs formas para percepção da questão conforme a natureza das causas motivadoras da evasão.

Nesse sentido, foi possível apresentar considerações que permitiram: (a) caracterizar as diferenças de contexto para análise da evasão no ensino superior; (b) alertar sobre os riscos institucionais de se adotar o índice de evasão escolar com pressupostos simplistas para análise; (c) propor uma forma para percepção da questão da evasão que identifica e separa os fatores entre controláveis e não controláveis; (d) apresentar alguns motivos para evasão escolar que estão fora do controle e outros que podem ser controlados em algum nível pelas instituições.

Com base nas distinções apresentadas, foi recomendado que para gerenciar a evasão deve-se, inicialmente, dimensionar a expressividade dos fatores motivadores da eva- 
são que estão "fora do controle" institucional. Essa margem de motivos "não controláveis" deve ser simplesmente aceita como variável ambiental, salvo caso surja alguma forma alternativa para entender a questão.

Alerta-se que diante de políticas educacionais que imponham metas inapropriadas de desempenho, há o risco de haver perda de qualidade nos cursos superiores, com prejuízo de longo prazo para a imagem institucional, derivado do uso de artifícios "impróprios" para diminuir a evasão escolar. Diante de metas exigentes ou inadequadas (e não questionadas), pode haver o desvirtuamento das práticas para cumprimento, tais como: "auxílio" nas notas e a desconsideração de freqüência e de prazos que deveriam ser observados pelos alunos. O prejuízo institucional pode ser elevado caso as metas equivocadas ligadas à evasão, utilizadas na avaliação, causem reduções no aporte de recursos.

Recomenda-se que futuras pesquisas busquem dimensionar a expressividade dos fatores (motivos) de evasão que estão dentro e fora da área de controle da instituição, como forma de permitir uma avaliação de metas mais adequada ao contexto brasileiro, regional, institucional e de cada curso, bem como sua evolução ao longo do tempo.

\section{REFERÊNCIAS}

BRASIL. Constituição da República Federativa do Brasil: promulgada em 5 de outubro de 1988.

Decreto n 6.096, de 24 de abril de 2007. Institui o Programa de Apoio a Planos de Reestruturação e Expansão das Universidades Federais - REUNI.

CRUZ, Flávio da; Glock, José Osvaldo. Controle interno nos municípios: orientação para a implantação e relacionamento com os tribunais de contas. 3. ed. São Paulo: Atlas, 2007.

GAIOSO, Natalicia P. de Lacerda. O fenômeno da evasão escolar na educação superior no Brasil. Universidade Católica de Brasília. Divulgado pelo Instituto Internacional para la Educación Superior en América Latina y el Caribe (IESALC), da UNESCO. Brasília/DF, 2005. Disponível em: < http://www.iesalc.unesco.org.ve/programas/Deserci\%C3\%B3n/Informe\%20Deserci\%C3\%B3n\%20Brasil\%20-\%20D\%C3\%A9bora\%20Niquini.pdf>. Acesso em: 12 out. $2007.75 p$.

GRUPO DE CONTATO - Tribunal de Contas da União (TCU); Secretaria da Educação Superior (SESu/MEC); e Secretaria Federal de Controle Interno (SFC). Manual de orientação para cálculo dos indicadores de gestão: Decisão TCU n 408/2002-Plenário. Versão revisada em janeiro/2006. $8 p$. 
INEP - Instituto Nacional de Estudos e Pesquisas Educacionais. Estatísticas sobre evasão escolar no Brasil - 1980 a 2002. Disponível em: <http://www.universia.com.br/html/ noticia/ noticia_clipping_gjij.html>. Acesso em: 07 out. 2007. Ano de 2002.

Sistema de Estatísticas Educacionais - EDUDATABRASIL. Censo da educação Superior - 2004. Disponível em: <http://www.edudatabrasil.inep.gov.br/>. Acesso em: 08 out. 2007.

MEC - Ministério da Educação. Diretrizes gerais do Programa de Apoio a Planos de Reestruturação e Expansão das Universidades Federais - REUNI. Agosto de 2007. Elaborado pelo Grupo Assessor nomeado pela Portaria n 552 SESu/MEC, de 25 de junho de 2007 , em complemento ao art. $1^{\circ}, \S^{\circ}$, do Decreto Presidencial $n^{\circ} 6.096 / 07$.

SCHIBIK, Silvia. O desafio de se manter na universidade. Banco Universitário do Portal Universia. Publicado em: 03 janeiro 2005. Disponível em: < http://www.universia.com.br/ html/materia/materia_gabi.html>. Acesso em: 08 out. 2007.

TCU - Tribunal de Contas da União. Acórdão TCU n 1.043/2006 - Plenário. Auditoria. Instituições Federais de Ensino Superior. Indicadores de Desempenho. Relatório Anual das Contas do Governo. Análise Setorial (...). 2006.

Decisão TCU n 408/2002 - Plenário. Auditoria Operacional. Relatório consolidado. Universidades federais. UNB. FUAM. UFGO. UFPE. UFRJ. UFRS. Elaboração de diagnóstico na área de ensino público superior. Levantamento de indicadores de desempenho [...].

UFSC - Universidade Federal de Santa Catarina. Relatório de gestão 2006. Disponível em: <http://www.pip.ufsc.br/relatorio.php>. Acesso em: 07 out. 2007.

UNIVERSIA. Ubes discute meia passagem em Curitiba. Clipping de matéria do jornal $O$ Estado do Paraná, publicado em 23 de março de 2007. Disponível em: <http://www.universia. com.br/html/noticia/noticia_clipping_dgeic.html>. Acesso em: 08 out. 2007. 